\title{
Prospects of the Components of Myanmar Food Control System for Health and Trade Efficacy
}

\author{
Wai Yee $\operatorname{Lin}^{1}$ and Masahiro Yamao ${ }^{2}$ \\ ${ }^{1}$ Post harvest Technology Application Center-PTAC, Directorate of Trade Promotion \\ Department, Ministry of Commerce(MOC), Myanmar, ${ }^{2}$ Food Production \\ Management Laboratory, Department of Bio Resource Science, Graduate School of \\ Biosphere Science, Hiroshima University, Japan, 1-4-4, Kagamiyama, Higashi \\ Hiroshima city, Japan
}

\begin{abstract}
Limited functional capacity and inadequate resources of government food control are common constraints in the export success of agricultural-resource-rich developing countries, thereby resulting to less competence in international food trade. The main sources of income for majority of the population depend on and directly relate with the success of primary food production and export. Thus, governments need to invest in food control system and other segments such as commodity standards formation, consistent quantity provision, and reliable inspection and laboratory services for trading system to be efficient. This paper presents SWOT factors identification of five key components of Myanmar food control system for tracing the process of food control works improved along with external pressures brought about by globalized food trade. Due to initial development stage of standardization activity, the technical regulation information gap between national standard body and trade promotion organizations in food trade was reported. The formation of National Quality Infrastructure has been in the process since 2012. Overall, there was a huge gap between food control governed by authority and food production industries. This paper stated nine strategies as recommendations. Law enforcement and the authorities' role in controlling should have to be reexamined for health efficacy. With regard to consumer participation, active-surveillance information flow should be encouraged so as to crack down and prevent dishonest trading and counterfeit goods productions inside the community. Finally, there were many rooms left for development of the components of the food control system for health and trade efficacy.
\end{abstract}

Keywords: Food control, coordination, food safety, export success

Correspondence : Wai Y.L. Address: Post harvest Technology Application Center-PTAC, Directorate of Trade Promotion Department, Ministry of Commerce(MOC), Myanmar Tel. No: +95-1-629043 E-mail: waiyeelin@gmail.com

DOI: 10.32945/atr3611.2014 


\section{INTRODUCTION}

\section{Food safety issues of developing countries in international food trade}

Reliable information availability of risks in food trade is often limited due to time-consuming chore, technical constraints, and new emerging diseases and outbreaks and so on. It makes unforeseen difficult in outcome prediction of hazards. So, Non-Tariff Measures-NTMs have been used for many years in international trade by import countries to protect health and trade concerns. Accordingly, agricultural export countries need investments in food safety and vertical integration of food control system to assure the quality of safe food.

However, developing countries often face limited functional capacity that imposes challenges in health and trade issues resulting to substantial economic shortfall. When it comes to food safety and Sanitary and PhytoSanitary SPS related issues, developing countries are usually placed at a disadvantage to access the best practice technology and information (Athukorala,2003). Approximately 80\% of problems faced by exporters of developing countries in world trade of 2010 were directly related with NTMs which is a major impediment to international trade and market access (WTO, 2012). Higher infrastructure investments driven by international trade make firms becoming more productive and better competence internationally (Gal Hochman, 2013). Thus, taking part in international trade demands government investments in trade related infrastructure such as technical regulations, products standards, etc. Governments' food control typically covers both domestically produced food and imported food (Jackson and Jansen, 2010) therefore the linkage between national food safety policy and trade have found useful to discuss food control measures (FSAI, 2006).

The participating countries in global trade have to live by international rules and consider major investments in food safety promotion and monitoring (Schillhorn and Veen, 2005). In this regard, standard is the important part of the governance structure of food system because their implementation determines how food is produced, processed and delivered to the consumer (Fulponi,2006). From industrial economics perspective, standard has impact on cost-efficiency and competition (Hammoudi, 2009). Table 1 shows some international, regional and local food control related organizations with their areas of concern. 
Table 1: Food control related organizations scaling down vertically from global to national

\begin{tabular}{llll}
\hline Level & Organizations/Committee/Institutions & Abbr. & Food control related with \\
\hline Global & World Health Organization & WHO & Health \\
& World Trade Organization & WTO & Trade \\
& Food and Agriculture Organization & FAO & Food control system \\
& World Organization of Animal Heath & OIE & Animal health \\
& International Plant Protection Convention & IPPC & Plant Protection \\
& CODEX Alimentarius Commission & CAC & Standard \\
& (established by WHO and FAO) & & \\
& Standard and Trade Development Facilities & STDF & Capacity building, \\
Regional & (established by WHO, FAO, OIE, WTO ) & & Technical assistance \\
ASsia, & ASEAN Expert Groups on Food Safety & AEGFS & Expert groups (Food Safety) \\
& ASEAN Task Forces on CODEX & ATFC & Tasks force (CODEX-Standard) \\
& ASEAN Consultative Committee on Safety \& & ACCSQ & Committee (Safety and Quality) \\
& Quality & & \\
& Asia and Pacific Plant Protection Commission & APPPC & Commission (Plant Protection) \\
National & ASEAN Committee on Consumer Protection & ACCP & Committee (Consumer Protection) \\
Fyanmar) & Food and Drug Administration & FDA & Food Control (Overall) \\
& Ministry of Science and Technology & MOST & Standardization \\
& Ministry of Industry & MOI & Food Industry \\
& City Development Council & CDC & Food Establishments/Street Foods \\
& Myanmar Agriculture Service (Plant Protection) & MAS-PP & Agriculture/Plant Protection \\
& Ministry of Livestock, Breeding, Veterinary, & MLBVF & Livestock/Animal Husbandry/ \\
& Fishery & & Fishery \\
& Ministry of Commerce & MOC & Trade/Consumer Protection \\
\hline
\end{tabular}

Food control authorities in Myanmar

Despite being the biggest country in mainland South East Asia and endowed with abundant natural resources, Myanmar remains one of the poorest countries in Asia. Nearly $70 \%$ of population reside in rural areas and approximately one third (32.7\%) of the population is under the poverty line (CIA, 2007). Primary food production has been historically an important livelihood for the majority of the population as the main source of income particularly in, agricultural sector.

Food and Drug Administration-FDA of the Department of Health-DOH under the Ministry of Health is the focal point of food control at the national level (Htwe).Being the food control authority of all domestically produced food and imported food, the FDA realized that risk analysis approach is of their concern (Htwe). Nevertheless, it had limited functional capacity as the main constraint (Htwe) though it is trying its best within its' existing capability in food control measures. The food control system has been established systematically in Myanmar, but the implementation of effective food control was still a critical issue for a developing country like Myanmar, up to now (Wai and Yamao, 2012b). Table 2 shows the chronological food control works implemented up to 2012. 
Table 2. Food control activities up to 2012.

\begin{tabular}{|c|c|}
\hline Year & Food Control Works \\
\hline 1927 & -food and drug control activities started \\
\hline 1928 & -the first Food and Drug Act enacted \\
\hline $1960 \mathrm{~s}$ & $\begin{array}{l}\text {-food control work was fragmented and exercised by various departments. } \\
\text { - then, Department of Health took responsibility for overall food safety }\end{array}$ \\
\hline 1972 & $\begin{array}{l}\text {-Public Health Law promulgated } \\
\text {-food quality control laboratory established }\end{array}$ \\
\hline 1992 & $\begin{array}{l}\text {-National Drug Law-NDL promulgated } \\
\text {-Board of Authority of Food \& Drug formed } \\
\text {-Food and Drug Supervisory Committees restructured according to the NDL }\end{array}$ \\
\hline 1995 & -Food \& Drug Division upgraded to a department under the Director \\
\hline 1997 & -National Food Law promulgated in line with WHO Model Food Law \\
\hline 2012 & -Amendment of The National Food Law proposed \\
\hline
\end{tabular}

Source: Adopted from FAO/WHO Regional Conference on Food Safety for Asia and The Pacific, Document 27

Aside from the food authority, trade authority-Ministry of Commerce MOC involves in managing food control with sub-ordinate position at trans-boundary trade. It supervises the issuance of export and import licenses by checking the recommendations from relevant ministries, standards or specifications, price and trademark for all imported and exported products (MOC). Imported food and food to be exported should be in compliance with the NFL and internationally recognized procedures, if trading is considered formal.

Standardization activities for all goods especially foods is at the infancy stage. The Myanmar Scientific and Technological Research DepartmentMSTRD had been paying attention mainly on metrology, while saying that standardization and quality control could not be practiced due to the early development stage of majority of the industries (MSTRD, 2012). The Ministry of Agriculture and Irrigation MOAI pays attention on the increasing yield of agriculture produces and shows very little concern on standards rather than SPS issues. The Ministry of Commerce plays the role for export promotion of agricultural produces. However, these ministries implemented their own policies with weak coordination and lack of sharing common goal, i.e. export success of agriculture commodities. Consequently, it was acknowledged by the MSTRD that there were technical regulation information gaps between the National Standard Body-NSB and the Trade Promotion Organization-TPO. It is fair to say that standardization activity in Myanmar could be observed not well appreciated. 
Even though, Myanmar aims at agriculture export for earning more foreign exchange and rural development, yet the success of export had been facing challenges especially with technical requirements issues such as lack of appreciation of commodity standards formation, insufficient resources in food control works, weak consumer protection affairs, etc. Aye (2005) mentioned that over $90 \%$ of major export crops such as pulses, maize were selling to countries with less rigorous SPS regulations. Such market failures call for government intervention with proactive policy to promote trade. All these segments such as formation of commodity standards, provision of consistent quantity, supporting reliable inspection and laboratory services are crucial for trading system to be efficient. In fact, food control serves as the assurance system for export. As regard to the safety of domestic foods, Htwe mentioned that the statistical data of the Central Epidemiological Unit (CEU) showed needs for attention of the authority concerning food safety especially for providing sanitary conditions.

\section{MATERIALS AND METHODS}

This research was carried out during March and April 2012 in Yangon, Myanmar. The Interview with the food authority was made by using semistructured questionnaires based on five key components of food control system to access the in-depth knowledge of food control provision. The initial context of Myanmar food control system was published by Wai Yee Lin and Yamao (2012). This paper presents SWOT factors identification of five key components of the system together with SWOT strategies for continuing further discussion, with respects to the result of the previously published paper, by focusing on health and trade interrelated issues. That identification was developed by FAO and WHO in 2003 based on extensive experience from many different national situations (Alomirah, 2010), and has been used in several food control studies. This paper is also based on intensive desktop analysis starting from 2011 up to the end of 2012, for tracing the process of food control works improved along with external pressures brought about by globalised food trade. The aims of this study are to identify the SWOT factors of the components of food control system for health and trade efficacy and to access how the concerned authorities: food and trade authorities, counteracted in response to recent food scares ,caused by smuggled contraband goods, which compromised health and trade interests. 


\section{RESULTS AND DISCUSSION}

This paper describes discussions on food control provisions and activities of the authorities concerned based on five key components of the food control system. Further discussions of food control works in accordance with five components of food control system are as follows:

\section{Food Law}

Updating the National Food Law -NFL was proposed in 2012, after 15 years of law enactment. It is an important step toward an effective of the food control system. This updating is in accordance with the common principle of food control system drawn by ASEAN and FAO organizations. The proposal for amendment of the National Food Law can be found as a huge step of progress, even though many more left to be tackled. Along with the market oriented economy after 1988, Myanmar had been involving more and more in international food trade, yet it was still struggling for fulfilling the requirements of profitable market with more straighten technical regulations.

The choice of goal for policy instrument was found focusing on the reduction of risk found on or in food such as pathogens or pest, rather than addressing the issue of food quality such as standards and information about products. That is the common policy choice made especially by developing countries.

Vested with power by the NFL to lay down policy for food safety related issues and to take action on those who do not comply with the regulations, the Board of Authority for food control was in place. However, when contaminated foods were found during post- market surveillance, the action taken was just confiscation from sellers and which was followed by destroying these goods and being publicized at newspapers. Thus, law enforcement and the authorities' role in controlling should have to be reexamined for achieving safety by efficient food control.

There was no separate defined and published policy on food safety as part of food policy.

\section{Food Control Management}

The approach used in food control management was the multi-agency approach with shared responsibility, while FDA was taking the main role of 
food control above all agencies. It served as one of the normal options that a country can practice depending on their capacity.

Food authority's control measures for import and export were in place resulting to sufficient provision for the formal trade. However, the huge amount of informal trade still existed at the porous border areas that were not under the control scope of food authority. This needed to be taken into account intensively from the food safety perspective.

As regard to post market surveillance, the existing way of taking action on contaminated foods was found as a one-time reactive measure. A number of questions arose concerning the provision of consumer protection and providing safe food achieved by mandatory regulatory food control activities of concerned authorities.

Regarding food control for domestic food production industries, food manufacturing factories and some small and medium sized food processing factories were under food control measures of the food authority with GMP and GHP certification systems, on the voluntary basis.

However, there were many forms of food productions left to be included under proper control. In fact, food safety concern of domestic food production was one of the serious issues to be tackled. For example: using industrial used dyes (unpermitted food color) in food production such as coloring of bamboo shoots, chili powder, turmeric powder, and using borax for preservation purpose in some food products, etc. were quite common. The production of counterfeit peanut oil was also one type of dishonest practices in food production lately. Hence, there was a huge gap between food control governed by authority and food production industries, if considering from food safety point of view. Continuous monitoring that suits with local condition, is needed to track and crack down the dishonest food production for the effectiveness of food control.

\section{Inspection Services}

In this component, it was found that FDA's inspection services focused more specifically on food factory inspection and pre \& post market surveillance for some varieties of food items in domestic market rather than covering all types of food.

At the border areas, the plant protection division of the MOAI operated seven entry-point inspection stations for inspections of agricultural products but worked with very limited technical capacity and facilities (Aye, 2005). In fact, there had been a number of challenges regarding safety 
aspect of contraband foods especially from China and Thailand border routes (Thu and Thein, 2012). Kubo (2012) mentioned that smuggling of goods into and from Myanmar was pervasive. Naturally, food safety may not be secured due to illegal trading through narrow paths sneaking out of the border trade zones and Customs, Immigration and Quarantine-CIQ check points.

Regarding other inspection teams, they were chosen depending on types of traded-foods, traders' preferences and importing countries' requirements. (For example: export commodity to Japan needs to be inspected by Overseas Merchandise Inspection Co., Ltd.-OMIC inspection team).The analysis results of food inspectors' perceptions showed that the existing food control at the system level needed more coordination with related departments for health and trade efficacy. According to interviews, majority of respondents from the inspection teams were found likely to achieve more strict control to be practiced, with regard to recent food scares.

\section{Laboratory Services}

Providing scientific information for supporting law enforcement and decision making should not be hindered due to insufficient resources (staffs, apparatus, equipment, etc.).Timeliness in the completion of analytical results had been a matter of concern for FDA's clients in the food industry who have to fulfill the requirements of the competitive market. Therefore, the FDA needed to take measures in capacity building matter to keep up with the demand of food industry. That led to delay in counteracting food scares. Indeed, laboratory service, the fourth part of food control system, is mainly about the initiative of government institutions. It is rather costly for government to protect consumers from adulterated food.

Concerned food control laboratories performed the food control measures with insufficient resources. Not all food control laboratories in Myanmar received good laboratory practices ISO-17025 certificate, the basic requirement for competency of testing and calibration laboratories. However, food control laboratories at the national level should address food safety issues with sufficient infrastructure, quality enforcement and monitoring system basically, regardless of how underprivileged the nation is. Achterbosch and Tongeren (2002) stressed the crucial role of public institutions' initiative that country level is an important playing field on the matter of food authority and inspection. 
Prospects of the components of Myanmar food control system

\section{Information, Education and Communication (IEC activities)}

The involvement of all stakeholders, especially consumers, in food control can be considered as one of the indicators of food control. Sonneveld (2005) suggested that countries need to establish the information, education, communication and training center to deliver advices and information for all stakeholders. IEC activities also show how government addresses by providing basic necessary infrastructures, quality monitoring system, and promoting information flow for food safety.

Regarding the role of Myanmar consumers, their participation in IEC activities was just being as the spectators in the form of Passive Participation in most cases. On the other hand, they themselves hardly complain. There was no association to advocate for consumers' rights up to 2012. One report mentioned that the cases detected concerning the adulterated food and drugs were from the sources of investigation works, routine and periodic checks and affected manufactures rather than patients' complaints and health professions reports (Zaw Dr. ,2007).Very little study had been done about consumers' perception on food safety. However, their concern over food safety is understandable.

There is a new focus on consumers' role in the food safety equation, both as actors and as advocates in the supply chain (Hanak et al., 2000). Involvement of all stakeholders, especially consumers' participation is very important, as it supports to gather information through activesurveillance information flow to prevent dishonest trading and counterfeit goods production (example: smuggling of contraband goods, production of counterfeit goods) inside the community. Active surveillance refers to the type of event-based surveillance by which data or information can be gathered by self-informing actively from the sources of community by themselves. This type of participation is effective for the situation at which the coverage of centralized food control system is insufficient. It should be encouraged through paving the way of community's participation in cracking down on food safety scandals.

It can be found that there were many rooms left to be developed and to encourage better participation of consumer in effective food control.

Myanmar food control system at the national level encompasses the fields of production, import, export, storage, distribution and sale of food to control and regulate by the concerned institutions with multi-agencies approach for the protection of consumers from counterfeit food. It has established all the fundamentals of food control system. However, 
legislation and functions are not confined to a single government department. Laws, Regulations, Standards, Enforcement and Analytical Services are shared by four main National Institutions and Departments.

Table 3 shows strengths and weaknesses of internal key components of the food control system and opportunities and threat from external factors. For strategic decision-making, SWOT method has been an essential tool in various contexts (Miika Kajanus et al., 2012) and is commonly used to systematically analyze organizations' internal or external environment (Gao and Peng, 2011).

Acknowledging the inadequacy of developing countries governments' resources, FAO, WTO and other international and regional organizations confer some necessary technical assistance in the development of food control authorities. In this regard, food control laboratories were organized starting from August 2012 by the initiative of the Asia Development Bank-ADB for forming the National Quality InfrastructureNQI systematically. The expert groups of ADB focused on four areas of Sanitary and Phyto-Sanitary-SPS activities such as: (1) animal hygiene, (2) plant hygiene, (3) food safety and (4) related support functions, aiming at assisting laboratories to be in line with international trading requirement and food safety (Samarajeewa, 2012). Some focus group discussions with laboratories technicians and other responsible personnel were made as the very first step in identifying the needs of capacity building and necessary infrastructures, for proposing the plan to meet the SPS requirements of Myanmar produces. Therefore, the formation of NQI has been in the process so as to participate in international trade more efficiently. Since adjustment for change is needed inevitably in implementing policy, this study has nine explanations as recommendations for better food control, shown in Table 4.

Due to the problems of food scares and the necessity of better food control as discussed, the current framework of food control was insufficient to cover various types of trade. It covered the conventional oversea trade only but it still needed to handle more intensively.

In later months of 2012, some progress had been made in the effort to control adulterated and smuggled food trade while paving the way for the informal trading activity to become a formal one by providing necessary measures to prevent the worsening of situation. Reform processes by the food authority and the trade authority were under way in the form of corrective action together with some ad-hoc activities. Table 5 shows some 


\section{more detailed steps forward made by these two authorities; however, there are still some shortcomings in the process.}

Table 3. Identification of SWOT factors of Food Control System Components.

Strength
I. Food Law
- Recent decision and effort to make amendment
of the NFL
- Recent proposal to approve new consumer
protection law
II. Food control management
-Food control system already existed
systematically
- Officials of related institutions acknowledged
the need of upgrading food control works

III. Inspection services

- Already in place

IV. Laboratory services - Already in place

V. IEC

- Already in place

VI. Others

- Ongoing effort on formation of the National Quality Infrastructures started in 2012

Opportunity

- Recent trans-boundary food scares ( ex: entering gutter oil ) made better attention of consumer on food safety matter

- Increasing pressure of local media in food safety and quality issues impacted positively on awareness of all stakeholders especially consumers

- Membership in WTO, CODEX, ASEAN food safety, ASEAN consumer protection affairs

- Booming businesses encouraged the development of food safety in food sectors

\section{Weakness}

I. Food Law

- Law enforcement was weak in practice

II. Food control management

-Limited capacity hindered in implementation of

effective food control system

- Not based on risk-based assessment

- Concerted efforts seen only when incidents occurred in the form of Ad-hoc activities

- Existing food control framework hardly cover informal border trade

- Standards and quality control activities were not well appreciated

III.Inspection Services

-FDA's food inspection covered very few food items

\section{IV.Laboratory services}

-Insufficient resources lead to time-consuming and slowed to counteract food related problem

V.IEC

- It was of low priority

- Weak in transparency

- Weak in interaction among stakeholders

- No consumer association organized yet

\section{VI.Others}

-Competing priority between food security and safety

Threat

- Limited confidence of foreign consumers and other countries governments in the safety and quality of domestically produced food

- Dishonest traders with adulterated commodity (ex: gutter oil)

- Demanding more straighten regulation for high-end consumer market access in international trade

Source : Survey conducted in 2012 
Table 4. Strategies for better food control of Myanmar.

\begin{tabular}{ll}
\hline Strategy & Explanation as recommendation \\
\hline Strength-Opportunities (S-O) & $\begin{array}{c}\text { 1. Increase the momentum of food control effort by taking the technical } \\
\text { assistance from International organizations by utilization of the food } \\
\text { control system established systematically }\end{array}$ \\
2. Identify all the root causes of problem to correct the policies \\
practiced, while political setting is in favor for change \\
3. Curb dishonest economic activities especially of trans-boundary food \\
scares by cooperation with regional or international bodies \\
4. Review the coverage of food control and procedures by discussion \\
with the related governmental agencies \\
5. Prioritize the needs of basic insufficient resources to correct the \\
failure \\
$\begin{array}{l}\text { 6. Foster transparency by adoption of co-management so as to } \\
\text { encourage the interaction among stakeholders }\end{array}$ \\
$\begin{array}{l}\text { 7. Advocate the use of IEC materials for active surveillance information } \\
\text { flow from consumers }\end{array}$ \\
8. Encourage private standard and certification systems for export \\
success \\
9. Cooperate with neighboring countries regarding cross border trading \\
issues
\end{tabular}

Source : Survey conducted in 2012

Table 5. Recent control measures by concerned authorities during 2012.

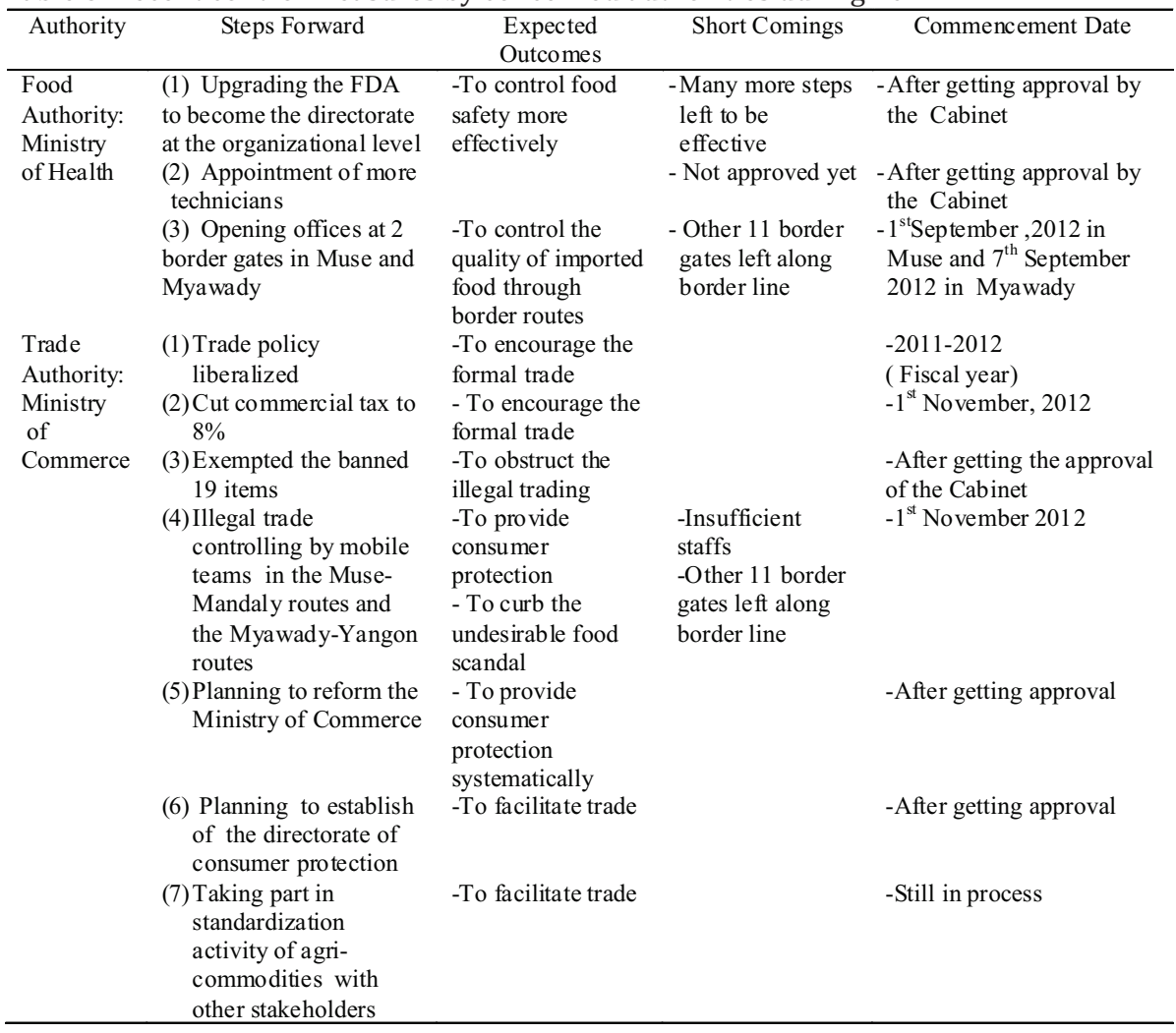

Source: Desktop Analysis from the secondary resources (2012). 


\section{CONCLUSION}

Export to countries with less rigorous sanitary and phyto-sanitary SPS regulations is evidently not the tactic way in globalizing trade that demands diversification. If Myanmar keeps lack of paying sufficient attention on standard and quality issues, exporters and farmers can enjoy very less profit margin compared to Myanmar produces re-exporters of other countries who can provide the necessary food control and SPS related requirements needed for high-end consumer markets. The growing level of Myanmar agricultural produces exports and the external threat of contraband imports showed the need of attention on proper food control policy by related government agencies (Wai and Yamao, 2012b). Supporting necessary food control measures with coordination efforts of the concerned agencies is vital to overcome the NTMs of the profitable market, in the long run. In upgrading the quality infrastructure to enjoy comparative advantages of specialized export commodity, strategy should be commensurate with the level of developments and should be achieved by government investments in food control to protect consumers' health and to take part in international trade effectively.

\section{REFERENCES}

ABDELHAKIM HAMMOUDI ,RUBEN HOFFMANN and YVES SURRY, 2009. Food safety standards and agri-food supply chains: An introductory overview. European review of Agricutural Economics, 36 [4]: 469-478.

ATHUKORALA PREMA-CHANDRA and JAYASURIYA SISIRA, 2003. Food safety issues and WTO rules: A developing countries perspectives, digitalcollection:1-30.

AYE THAN,2005. Sanitary and Phyto-sanitary(SPS):Union of Myanmar, Asian Producivity Organization,2005.

CHAN MYAE THU and KO SHWE THEIN (Myawady), 2012. FDA laboratory starts operation to issue recommendation for import liscense at Myanmar-thailand and Myanamr-China border gates. (2012,September,21).Eleven Journal. 
CHANG-YUAN GAO and DING-HONG PENG. (2011).Consolidating SWOT analysis with nonhomogeneous uncertain preference information. Knowledge-based System,24[6]:796.

CIA, 2007.Central Intelligence Agency, Facts sheets.2012, $\mathrm{N}$ ove m b e r, $20, \mathrm{w}$ w w. c i a.g ov / : h t t p s : / / w w w . cia.gov/library/publications/the-world-factbook/geos/bm.html.

FAO,2006. Strengthening national food control systems: Guidelines to assess capacity building needs. Rome

FAO, 2007. Strengthening national food control systems: A quick guide to assess capacity building needs. Rome

FULPONI LINDA, 2006. Private voluntary standards in the food system: the perspective of major food retailers in OECD countries. Food policy,31[1]2.

GAL HOCHMAN TABAKIS and DAVID ZILBERMAN CHRYSOSTOMOS, 2013. The impact of international trade on institutions and infrastructure . Journal of Comaparative Economics 41:126-140

GMS MYANMAR,2009.Greater Mekong sub-region economic cooperation program,Myanmar: Country Assessment on Biofuels and Renewable Energy.

HANAK E,BOUTRIF E,FABRE and PINEIRO M. ,2002.Food Safety Management in Developing countries, International workshop CIRADFAO. Montpellier, France.

HTWE DAW YI YI,Regional Conference on Food Safety for Asia and the Pacific, MyanmarCouintry Report.FAO/WHO.Document 27.

JACKSON LEE ANN and JANSEN MARION, 2010. Risk assessment in the international food safety policy arena.Can the multilateral institutions encourage unbiased outcomes? Elsevier,35[6] 538 
Prospects of the components of Myanmar food control system

KAJANUS, M., LESKINEN, P., KURTTILA, M.and KANGAS, J, 2012. Making use of MCDS methods in SWOT analysis, Lessons learnt in strategic natural resource management. Forest Policy and Economics,20:1-9.

KUBO KOJI ,2012.Real exchange appreciation,resources boom and policy reform in Myanmar.IDE, BRC,JETRO Bangkok, 11.

LWIN PHYU PHYU, 2011. Plant protection profiles of Myanmar. Plant protection profiles from Asia-Pacific Countries (2009-2010), Rap Publication 2011-11.Bangkok, Thailand,FAO Regional Office for Asia and the Pacific: FAO.

MOAI,2009-2012. www.moai.gov.mm/,2012,December,29th, http://www.moai.gov.mm/

MOC,2012. Ministry of Commerce,Myanmar. Retrieved June 20, 2012, from http://www.commerce. gov.mm/.2012,0ctober,10th,Ministry of Commerce,Myanmar.http://www.commerce.gov.mm/index. php? option=com_content\&view=article\&id=263\&Itemid=189\&lang=en

MOST,Scientific and Technological Research Department MSTR,Myanmar, Quality Management: Linking TPOs and NSBs for export success. $10^{\text {th }}$ January,2013,www.intracen.org/Work Area/

OO NAING YE.2012. FDA will be upgraded as the seperate directorate, not under the directorate of health (2012,December,17th) The Voice Weekly, Institutional.

SAMARAJEEWA UPALI,2012. Focus group discussion on testing and accredition laboratory capacity development . (2012,October $\left.24^{\text {th }}\right)$ Yangon, Myanmar: ADB.

SEIN U THEIN,2012.World countries need to increase food production, improve distribution to feed entire population sufficiently. (2012,November,6th) 9th Asia-Europe Meeting Summit. 
SONNEVELD CORNELIS,2005.Measures for enhancement of food safety and quality assurance systems for enhanced trade, Aisan Productivity Organization. 2005.

SHWE WAR LWIN and HLAING KYAW SOE,2012. http://www.mmtimes .com/index.php/national-news/2849-mobile-teams-to-crackdown-oncontraband.html.

THOM ACHTERBOSH and FRANK VAN TONGEREN,2002. Food safety measures and developing countries: Literature review. Hague, Netherland:1-53

UNKNOWN AUTHOR,2012.FDA tested goods for import health certificates in border towns.(2012, November5th).2012,December,10:www. elevenmyanmar.com/business:http://www.Elevenmyanmar.com/busin ess/1181-fda-tested goods-for-import-health-certificates-in-bordertowns.

WAI YEE LIN and MASAHIRO YAMAO, 2012b. An assessment of food control system and development perspectives: the case of Myanmar. World Academy of Science,Engineering and Technology, 69: 751-756.

WT0,2012. World Trade Report,Trade and public Policies: A closer look at non-tariff measures in the $21^{\text {st }}$ century

ZAW DR.TUN. 2007. Country report of Myanmar . First ASEAN-China Conference on Combating Counterfeit Medical Products. (2007,November,13-15) Jakata, Indonesia. 